\title{
Prácticas discursivas orales, dialectos e identidad social*
}

\author{
ÉDER GARCÍA DUSSÁN** \\ eagarciad@udistrital.edu.co
}

Recepción: 10 de noviembre de 2014

Aprobación: 21 de enero de 2015

Forma de citar este artículo: García-Dussán, É. (2015). Prácticas discursivas orales, dialectos e identidad social. Cuadernos de Lingüística Hispánica, 26, 49-74, Tunja: Uptc.

* Este artículo de investigación hace parte del proyecto investigativo "Textos creativos y la identidad social en Colombia" (20132015), auspiciado por el Centro de Investigaciones y Desarrollo Científico (CIDC) de la Universidad Distrital, "Francisco José de Caldas"; código 4-543-384-13.

** Filósofo de la Universidad Nacional de Colombia; Magíster en Lingüística Española del Instituto Caro y Cuervo y Magíster en Filología Hispánica del Instituto de Lengua Española (CSIC, España). Pertenece al Grupo de Investigación Lenguaje, identidad y Cultura (GLIC) de la Universidad Distrital, "Francisco José de Caldas", Colombia. 


\title{
Resumen
}

Este artículo explica unas categorías que auxilian la descripción y el análisis de los mundos gestual y corp-oral, con el fin de aprovecharlas en beneficio del desarrollo de una tesis conocida en sociolingüística: las lenguas viven en las prácticas discursivas y reflejan elementos socioculturales de sus hablantes. De esta suerte, al conocer fenómenos, en cualquier nivel de la lengua, hay posibilidades más seguras hacia la comprensión profunda de los rasgos de una cultura. Esta tesis se pone a prueba con dos ejemplos, frecuentes en la comunicación entre colombianos, un gesto-batuta y una conducta corporal frente a espacios urbanos, y se concluye desde dos dimensiones: (i) una teórica, que revela la posibilidad de ratificar cómo el análisis de los niveles de la lengua son también el vehículo de la búsqueda de claves sobre la identidad social de un pueblo, y (ii) una práctica que reitera una cualidad social local: la interacción violenta entre socios y la consecuente imposibilidad de la armonía y la paz sociales, asentada en la imagen del fuerte, del hombre vigoroso y valiente.

Palabras clave: lengua, nivel prelingüístico, práctica discursiva oral, quinesia, proxemia, dialecto gestual, dialecto proxémico, cultura del bravío.

\section{Oral discursive practices, dialects and social identity}

\begin{abstract}
This article explains a series of categories which are helpful in the description and analysis of gestural and corp-oral worlds, which can be employed in the development of a well-known sociolinguistic thesis: languages dwell in discursive practices and reflect socio cultural features of their speakers. Thus, identifying phenomena on any level of language enables a deeper comprehension of the features of a culture. This thesis is tested with two frequent examples in communication among Colombians, the pointing gesture and bodily behavior facing urban spaces. Conclusions are reached on two levels: (i) a theoretical one, which ratifies analysis of the levels of language as a vehicle for finding clues about social identity and (ii) a practice that reaffirms a local social quality: violent interaction among partners and the consequent impossibility of social harmony and peace, rooted in the image of man as strong, vigorous and brave.
\end{abstract}

Key words: Language, prelinguistic level, oral discursive practice, kinesics, proxemics, gestural dialect, proxemic dialect, machismo culture. 


\section{Pratiques discursives orales, dialectes et identité sociale}

\section{Résumé}

Cet article explique des caractéristiques qui assistent la description et l'analyse des mondes gestuel et corp-orel, afin d'en profiter au bénéfice du développement d'une thèse connue en sociolinguistique: les langues vivent dans les pratiques discursives et reflètent des éléments socioculturels de leurs usagers. De cette sorte, une fois les phénomènes connus, dans n'importe quel niveau de la langue, il y a des possibilités plus sûres vers la compréhension profondes des traits d'une culture. Cette thèse est mise à l'épreuve avec deux exemples, fréquents dans la communication parmi les colombiens, un geste-canne et une conduite corporelle vis-à-vis des espaces urbains ; et la thèse est conclue à partir de deux dimensions : (i) celle qui est théorique, qui révèle la possibilité de ratifier comment l'analyse des niveaux de la langue, véhicule la recherche de clés sur l'identité sociale d'un peuple et, (ii) celle qui est pratique qui réitère une qualités sociale locale: l'interaction violente entre des associés et la conséquente impossibilité de l'harmonie et la paix sociales, affirmée sur l'image du fort, de l'homme vigoureux et courageux.

Mots clés: langue, niveau pré-linguistique, pratique discursive orale, kinésie, proxémie, dialecte gestuel, dialecte proxémique, culture du sauvage.

\section{Práticas discursivas orais, dialetos e identidade social}

\section{Resumo}

Este artigo explica umas categorias que auxiliam a descrição e a análise dos mundos gestual e corp-oral, com a finalidade de aproveitá-las em benefício do desenvolvimento de uma tese conhecida em sociolinguística: as línguas vivem nas práticas discursivas e refletem elementos socioculturais de seus falantes. De forma que, ao conhecer fenômenos, em qualquer nível da língua, há possibilidades mais seguras para a compreensão profunda dos rasgos de uma cultura. Esta tese é posta a prova com dois exemplos, frequentes na comunicação entre colombianos, um gesto-batuta e uma conduta corporal frente a espaços urbanos, e se conclui desde duas dimensões: (i) uma teórica, que revela a possibilidade de ratificar como a análise dos níveis da língua é também o veículo da busca de chaves sobre a identidade social de um povo e, (ii) uma prática que reitera uma qualidade social local: a interação violenta entre sócios e a consequente impossibilidade da harmonia e da paz sociais, assentada na imagem do forte, do homem vigoroso e valente.

Palavras chave: língua, nível pré-linguístico, prática discursiva oral, quinesia, proxémia, dialeto gestual, dialeto proxêmico, cultura do bravio. 


\section{Introducción}

El lingüista francés Emilio Benveniste, siguiendo el camino despejado por De Saussure, estudió la lengua como un "sistema orgánico de signos". Aún más, expuso que las operaciones que permiten efectuar un análisis de las unidades discretas de ese sistema son la segmentación y la sustitución. La primera operación, valorable en el eje sintagmático, permite descomponer un texto en unidades cada vez menores (oración > palabras $>$ formas con sentido $>$ sonidos distintivos), mientras que la segunda operación, la sustitución, propia del eje paradigmático, permite reemplazar una unidad por otra equivalente (Benveniste, 1989).

Esto permite comprender que las lenguas son sistemas que remiten a una complejidad; lo cual significa que su organización no equivale a una estructura única, sino a varias que se complementan solidariamente y establecen relaciones mutuas entre sí. Estos subsistemas, también llamados macro-niveles, son el prelingüístico, que incluye la quinesia y la proxemia (gestos, posturas, miradas, sonrisas, movimientos de antebrazos y manos, formas de vestir, etc.); el paralingüístico, que contiene todos los fenómenos prosódicos (acentuación, proyección de la voz, entonación, ritmo, líoros como los sollozos, etc.) y, finalmente, el nivel lingüístico, que se apoya en el léxico y la gramática para construir matrices simbólicas supra-oracionales.

Ahora bien, según la norma propuesta por el profesor emérito de la Universidad UCLA Albert Mehrabian (1972), en aquellos entornos explícitos en que la comunicación verbal es equívoca o imprecisa, solo el $7 \%$ de la información se atribuye a las palabras, mientras que el $38 \%$ se atribuye a elementos paralinguísticos y el 55\%, a elementos quinésicos y proxémicos. Dicho de otra forma, entre los elementos prelingüísticos y los paralingüísticos hay un 93\% de recursos comunicativos que se juegan cuando hay ambigüedad tanto en el uso de los lexemas y sus reglas de organización interna (sintaxis y semántica) como en la formación externa (pragmática). De hecho, esta es, justamente, una de las principales diferencias lingüísticas entre la modalidad oral (habla y escucha) y la escrita (lectura y escritura): en aquella predominan los niveles pre y paralingüísticos a la hora de generar textos aprovechables para la comunicación. 
Efectivamente, en la modalidad oral de las lenguas el componente no verbal juega un papel muy significativo junto con el entorno o contexto ${ }^{1}$, dado que auxilian procesos de desciframiento y construcción de los sentidos de las ideas que se comunican en las diferentes situaciones comunicativas. De esta suerte, como indican Calsamiglia y Tusón (2002), lo que caracteriza la modalidad oral es su:

- Dependencia del contexto situacional

- Espontaneidad

- Carácter interactivo, afectivo y co-constructivo de la comunicación

- Registro diafásico informal

- Uso de información implícita (presupuestos y sobreentendidos)

Uso de elementos de las lenguas, de cualquier nivel, que un hablante señala y que el oyente recibe e interpreta, y que son llamados "indicios contextualizadores" (Gumperz,1982) como, por ejemplo, el tono de la voz, la selección léxica, la elección de unas cualidades morfofonéticas y gramaticales determinadas, el cambio de lengua (LM a LE o L2), los juegos de miradas, ciertos gestos, las posturas corporales y otros similares.

Así las cosas, dada la esencial preeminencia de todo aquello que concierne al mundo quinésico, a propósito de los análisis de las prácticas discursivas orales, nos concentraremos en desplegar los elementos básicos de esta dimensión del nivel prelinguístico, para luego desarrollar dos conceptos fundamentales, el de frontera gestual y el de idiolecto gestual, revisando su funcionalidad analítica con ejemplos que prepararán el terreno para fijar la atención en dos ejemplos concretos en Colombia: el gesto ilustrador regional de cobardía y la postura proxémica evasiva en los espacios urbanos de las megalópolis, lo cual permitirá obtener algunas conclusiones sobre nuestra identidad social al seguir el precepto sociolingüístico que sostiene que la lengua-idioma refleja la cultura, por lo menos, parcialmente.

\section{Referentes teóricos}

Ha sido labor de hace pocos lustros el estudio persistente del nivel prelingüístico de las lenguas y, a pesar de su poca tradición temporal, es un área rica en problemáticas y en autores; entre ellos sobresalen los estudios de la psicóloga comunicativa Flora Davis (1989) y del zoólogo británico Desmond Morris (2009), como también los aportes de la naturalista Diane Ackerman (2000), al igual que la contribución de los profesores

1 Comprendemos por contexto tanto el soporte físico o decorado en el que se realiza la enunciación, como también el escenario (aquí y ahora); por lo que incluye "todo aquello que, física o culturalmente, rodea el acto de enunciación" (Escandell, 2005, p. $31)$. 
Mark Knapp (1982), cuya obra ha sido traducida a seis idiomas, y Phillipe Tourchet (2010), conocido por crear la Sinergología, disciplina para conocer al interlocutor a través de sus gestos. A esta lista, es urgente sumar a Fernando Poyatos (1994) y Martha Albaladejo (2007), quienes centran la atención en la lengua española. En este apartado nos propondremos considerar el despliegue taxonómico de categorías y subcategorías propicias para la descripción y análisis de los elementos quinésicos y proxémicos, útiles en investigaciones que atañen a estos niveles de lengua oral, pues constituyen " [...] un estado primitivo previo a toda forma de interpretación semántica, sintáctico-morfológica y pragmática" (Jorques, 2004, p. 74).

Suele ser un lugar común creer que gestos y posturas son irrelevantes en la comunicación en vivo, que son unos añadidos triviales; sin embargo, al estudiar juiciosamente las disciplinas que abordan estas conductas, se descubre que su importancia y funcionalidad obedecen a una complejidad extraordinaria, y admiten indagaciones y clasificaciones extensas, pero limitadas. Así, por ejemplo, Morris afirma que "cada uno de los cinco dígitos de la mano tiene su propio significado y sus gestos característicos" (2009, p. 198), mientras la psicóloga Davis (1989) detalla que:

Se pueden lograr setecientos mil signos diferentes usando combinaciones de movimientos del brazo, de la muñeca y de los dedos [...] los movimientos de las manos también son económicos, rápidos de emplear y pueden ejecutarse con mayor velocidad que el lenguaje verbal (p. 111).

Por cierto, el profesor emérito de la Universidad de Texas, Mark Knapp (1982), diferencia los arquetipos de comunicación no verbal. Inspirados parcialmente en su taxonomía, reconstruimos y proponemos una tipología ajustada, a saber:

- Las conductas quinésicas, básicamente los gestos y movimientos corporales (manos, cabeza, pies, piernas, expresiones faciales y la mirada).

- El físico (forma del cuerpo y del rostro, altura, peso, cabello, color y tonalidad de la piel, etc.).

- La comunicación olfativa (olores corporales, aliento, uso del perfume, de labiales y equivalentes).

- La comunicación táctil (caricias, golpes, etc.).

- Las conductas proxémicas o el uso y percepción del espacio social y personal.

- Las conductas paralingüísticas o relativas a los rasgos suprasegmentales de las lenguas (tono, timbre, intensidad y duración). 
- Los factores del entorno (estilo de decoración del hogar, condiciones de luz, olores ambientales, música de fondo, etc.).

Ahora bien, de estos siete tipos de comunicación no verbal, para efectos de este texto, nos concentraremos en las conductas quinésicas y proxémicas, dada la importancia que evidencia en las prácticas orales cotidianas, especialmente cuando se desea analizar conversaciones espontáneas donde el orden y la duración de los turnos no es fijo, el número de hablantes es variable y donde se usan indicios contextualizadores que orientan el proceso (pedir la palabra, saber qué está pasando, alianzas, etc.).

\subsection{La quinesia}

La concepción de los gestos ha estado sujeta a una reflexión que tiene una historia íntimamente relacionada con la moral. Por ejemplo, en la antigua Roma, la palabra latina 'gestus' estaba asociada con la de 'modestia'. Ser modesto consistía en evitar cualquier exceso (ne quid nimis: que no haya nada de más). Para los clásicos y para los cristianos, 'modestia' era sinónimo de 'temperantia', la cual, ya para Cicerón (2006) consistía en realizar cualquier acción y pronunciar cualquier palabra con orden y medida. Así, pues, para Cicerón los movimientos y actitudes del cuerpo, el estar parado o andando, la forma de sentarse y apoyarse, la expresión de los ojos y de la cara, el movimiento de las manos y los gestos visibles daban cuenta del espíritu y nobleza de los sujetos. Gracias a esta tesis, se recomendaba que tanto los gestos, como la forma de caminar no debían ser ni muy enérgicos ni muy afeminados, haciendo que la única regla fuera la del justo medio (medius-ocris: el que se queda en la mitad de algún lugar), y ahí residía la virtud capital en la antigüedad: la mediocridad es lo mejor. Como afirma el escritor mexicano Gabriel Zaid:

La sabiduría antigua desconfiaba de la desmesura, lo desproporcionado, el exceso. Esta desconfianza llegó a convertirse en un elogio de la medianía y la moderación. Aristóteles define la virtud como el justo medio entre dos extremos (Ética nicomaquea, II, p. 6). Horacio celebra la dorada medianía (Odas, pp. 2, 10). Séneca engrandece el desprecio a la grandeza: "Es de gran ánimo despreciar las cosas grandes y preferir lo mediano a lo excesivo" (Cartas a Lucilio, p. 39). Todavía a principios del siglo XVII, Montaigne casi lo cita: La grandeza "muestra su altura en preferir las cosas medianas a las eminentes" (Ensayos, III, p. 13). Por esos años, Covarrubias, en el Tesoro de la lengua castellana o española, anota que medianía "Se dice de lo que es razonable y puesto en buen medio. Mediocridad es latino, significa lo mismo y úsanle algunos" (2005, p. 32). 
Ahora, siguiendo al profesor medievalista Jean-Claude Schmitt (1990), los padres de la iglesia redefinieron esta virtud cardinal y le sumaron las virtudes cristianas: fe, esperanza y caridad ${ }^{2}$. Schmitt relata que es San Ambrosio, hacia el siglo V, quien definió en términos de 'modestia'-'temperantia' la virtud cristiana del gesto; pero tras su muerte la palabra 'gestus' desapareció del vocabulario coloquial, dado que se asoció con el menosprecio por el cuerpo, foco del pecado y, por tanto, del mal. En el siglo XII reaparecen 'gesticulatio' y 'modestia', imponiéndose como virtud específica asociada al gesto. Para el monje francés y Doctor de la Iglesia San Bernardo (1984), el hombre traicionero mira hacia todos lados siempre, el hombre perverso guiña los ojos y los movimientos exagerados del cuerpo son síntomas de que esa alma ha sucumbido al mal; aún más, afirmaba que reírse a carcajadas era un acto abominable, pues manifestaba una falta de control, controversia desarrollada por Umberto Eco en la afamada novela que ambienta una abadía benedictina en el siglo XIV (1983) ${ }^{3}$.

Sin embargo, la cultura filosófica del siglo XII se complementó en las escuelas urbanas, especialmente con la figura de Bernardo Silvestre, cuya influencia fueron las ideas de Cicerón. Su tratado "Morales philosophia de bonesto et utili" (citado en Schmitt, 1990) presenta la virtud de la templanza subdividida en ocho categorías, entre las cuales la 'modestia' era definida como la virtud que mantiene todo movimiento de la actividad humana, subrayando, así, que "todo movimiento corporal es el reflejo de lo espiritual", mientras que la 'verecundia' es "fruto del bien moral en el gesto, la palabra y la expresión del rostro" (Schmitt, 1990, p. 137). Nuevamente, la gran enseñanza era que se debía moderar el gesto, de tal forma que mientras se esté hablando ante el otro, no se muevan los miembros desordenadamente ni se desajuste el tono sereno en la enunciación.

Ahora bien, este tipo de reflexiones sobre la gestualidad, atadas a ideologías religiosas de la Edad Media, se siguen perpetuando en la actualidad, pues aún se piensa que la mirada refleja cierta espiritualidad de alguien, como también se sigue especulando, a la mejor manera de un repertorio común heredado, que los gestos expresan la esencia de quien los ejecuta. Dicho de otra forma, los modales no son simples convenciones sociales, sino morales. Para nadie es un secreto que la torpeza al hablar, al comer, al reír e, incluso, al caminar, revela elementos de lo que se puede pensar y esperar de la persona

2 Así se puede confirmar en la Primera epístola del Apóstol San Pablo a los Corintios: 13, 13: "Y ahora permanecen la fe, la esperanza y el amor, estos tres; pero el mayor de ellos es el amor (caridad)".

3 En El nombre de la rosa, el profesor italiano Eco relata los homicidios relacionados con la existencia del segundo libro de la Poética de Aristóteles, dedicado a la risa, obra oculta en la biblioteca del monasterio. Allí el anciano Jorge de Burgos protege ese secreto y es Guillermo de Baskerville quien revela el enigma. El centro de todo el conflicto es, pues, la risa, la cual es defendida por Aristóteles por poseer poderes liberadores, pero una amenaza para Jorge, pues es signo de la debilidad, corrupción e insipidez de la carne, a tal punto que para él es una aliada del Anticristo, que permite perder el miedo a la muerte y al demonio. 
que actúa de esta forma. Lo que de aquí quedó de ese período es, entonces, una forma primaria de asumir la reflexión sobre los gestos y su función comunicativa; de suerte que los gestos, al ser muchas veces inconscientes, "dicen” más, y con mayor transparencia, que un discurso.

Actualmente, la forma de estudiar los gestos no solo contiene elementos de las concepciones moralista y esencialista, sino también implica una perspectiva lingüística impulsada por la famosa norma Mehrabian (7-38-55) arriba citada; esto es, permite entender los gestos y las posturas corp-orales como unidades de análisis variantes, al lado de los fonemas, los morfemas, los lexemas, los semas, los textemas y los actos de habla. Es así como se admite una labor de descripción a través de una clasificación de las conductas quinésicas y proxémicas. Al respecto, se pueden encontrar varias propuestas taxonómicas, como la que recuerda Jorques (2004), y que relacionan el signo y el objeto referido, permitiendo hablar de tres grandes tipos de gestos:

- Naturales, que reposan bajo el valor de índice, como el caso de secarse la frente como indicio de transpiración.

- Descriptivos, que descansan con el valor icónico, como la imitación de un revólver con la mano.

- Simbólicos, que reposan bajo el valor convencional, como el caso de levantar el brazo a la llegada de un autobús.

No obstante, esta invitación resulta muy general si se piensa en las interacciones propias de escenarios comunicativos escolares, por caso; de suerte que nos parece más acertada la propuesta de la filóloga española Albaladejo (2007) en relación con la función que cumplen los gestos y posturas en la comunicación, y que resumimos a continuación, complementándola con algunas ideas de Morris (1977): 


\begin{tabular}{|c|c|c|c|}
\hline & Quinema & Cualidad & Ejemplos \\
\hline \multirow[b]{5}{*}{$\begin{array}{c}\text { Gestos } \\
\text { conscientes }\end{array}$} & Emblemas & $\begin{array}{l}\text { Sustituye palabras, lo cual refuerza la } \\
\text { iconificación de la comunicación. }\end{array}$ & $\begin{array}{l}\text { El dedo índice en frente de los labios para } \\
\text { indicar silencio, el gesto de 0.K. con la } \\
\text { mano. }\end{array}$ \\
\hline & $\begin{array}{l}\text { Ilustradores } 0 \\
\text { 'ademanes de } \\
\text { batuta' }\end{array}$ & $\begin{array}{l}\text { Acompañan y puntúan el discurso } \\
\text { verbal. Se les llama 'batuta' porque } \\
\text { marcan el ritmo del discurso. } \\
\text { (Este es emocionalmente neutro) }\end{array}$ & $\begin{array}{l}\text { Palmotear la espalda del otro, mientras se } \\
\text { saluda; los movimientos de antebrazos y } \\
\text { manos mientras se hace una charla. }\end{array}$ \\
\hline & Patógrafos & Manifiestan emociones. & $\begin{array}{l}\text { Alzar los brazos generando una enorme } \\
\text { "V" de victoria. }\end{array}$ \\
\hline & Reguladores & $\begin{array}{l}\text { Controlan la interacción } \\
\text { conversacional o turnos de habla, } \\
\text { desde su apertura, hasta su cierre. }\end{array}$ & $\begin{array}{l}\text { Levantar la mano para pedir la palabra, } \\
\text { besos, apretones de mano, mirada } \\
\text { mantenida o desviada. }\end{array}$ \\
\hline & Adaptadores & $\begin{array}{l}\text { Ayudan a satisfacer necesidades } \\
\text { personales y adaptarnos a la situación. }\end{array}$ & $\begin{array}{l}\text { Acomodarse el nudo de la corbata o las } \\
\text { gafas mientras se habla, hurgarse } \\
\text { frotarse la nariz, tocar reiterativamente al } \\
\text { receptor, chupar el bolígrafo. }\end{array}$ \\
\hline $\begin{array}{l}\text { Gestos } \\
\text { inconscientes }\end{array}$ & Gesticulación & Gestos involuntarios y/o automáticos. & $\begin{array}{l}\text { Frotarse la quijada o acomodarse el pelo } \\
\text { detrás del lóbulo de la oreja en situaciones } \\
\text { que generan estrés. }\end{array}$ \\
\hline \multirow{2}{*}{$\begin{array}{c}\text { Gestos } \\
\text { conscientes } \\
\text { y/0 } \\
\text { inconscientes }\end{array}$} & Mirada & \multirow[b]{2}{*}{ Transmiten emocionalidad. } & Mirada perdida. \\
\hline & $\begin{array}{l}\text { Expresiones } \\
\text { faciales }\end{array}$ & & Expresión de felicidad. \\
\hline
\end{tabular}

Cuadro 1. Tipología de quinemas. Elaboración del autor.

Sobre esta codificación, hay que advertir que, la mayoría de las veces, los quinemas emergen en las conversaciones cotidianas espontáneas de forma combinada; así, por ejemplo un emblema, en algún momento, puede adquirir la dimensión de un ilustrador o de un patógrafo, de la misma manera que un patógrafo o una gesticulación se puede manifestar al tiempo de forma emblemática o en forma ilustrativa. Por otra parte, un adaptador puede adquirir la condición de un emblema o fácilmente se puede encontrar un regulador, tomando la cualidad de ilustrador simultáneamente. Ahora, esta situación lejos de ser problemática, resulta útil para el trabajo descriptivo de un análisis pre-lingüístico sobre un corpus determinado, ya que, muchas veces, cada quinema requiere de un apoyo incondicional del otro para combinarse con las dimensiones fónica y semántica del código verbal.

Ahora, si se piensa en formas concretas para describir gestos, se logra imitando la técnica lexicológica de artículos como los que aparecen en los diccionarios actuales, que fijan una entrada o concepto por definir y luego de ofrecer una información lingüística, 
muestran denotaciones y acepciones. Para nuestro caso, las entradas no son palabras, sino imágenes de gestos, para lo cual es viable también detallar elementos como el número de la acepción y la definición, dependiendo de la marcación diatópica. Sobre esto ya hay un primer ejercicio, logrado por el profesor italiano Giovanni Meo-Zilio y por Silvia Mejía, autores del Diccionario de gestos (1980), esfuerzo que estableció el repertorio léxico-gestual del que dispone una comunidad unida por una misma lengua. A manera de ejemplo, trascribimos el siguiente artículo:

24.1 Las manos abiertas y paralelas en un plano horizontal, palmas hacia abajo (o también partiendo de una posición cruzada de las muñecas) se desplazan simultánea y lateralmente con tensión enérgica y mov. seco y amplio de unos 2030 cts., quedando luego inmóviles por unos segundos: Arg. (“FFínish!”). Bol., Col. (“'No más!”) Costa R., Cuba ("jSe acabó lo que se daba!”) Ch., Ec., (Sign. También DESAPARICIÓN; PERFECTO; CORRECTO): Esp. Guat., Hond., Nic., Par. Pan. (como Ec.) $(1980,50, \mathrm{~T} 1)$.

Esta codificación gestual, suele completarse con otros quinemas, a saber: la mirada y las expresiones faciales. En cuanto a la mirada, resulta un elemento seductor en relación con los posibles usos en la comunicación no verbal. Como es sabido, es muy difícil describirla; de suerte que la mayor parte del tiempo se fracasa en un intento de responder a la pregunta cotidiana “¡Por qué me miras así?”. En todo caso, lo único cierto es que existe la certeza que la mirada comunica, especialmente información de tipo emocional: tristeza, alegría, ira, irritación, preocupación, deseo, timidez, excitación, y similares. Pero, también comunica ciertos estados esenciales del sujeto; en este orden de ideas, se dice que hay una mirada pícara, sensual, ingenua, dulce, espiritual, etc. Y, al lado de la información emocional, también se estudia la dirección de la mirada que suele indicar aprecio, atención o estados mentales de pensamiento abstracto, como es el caso de la afamada 'mirada al vacío' o la 'mirada perdida' que, dependiendo del contexto, puede significar estados de alta concentración o ensimismamiento (acompañada de gestos como fruncir el entrecejo o de cruzar los brazos) o patologías cognitivas.

Por otra parte, se habla del poder de la mirada, creencia que se remonta a la Roma de Virgilio (1990), quien culpa al "mal de ojo" por la flaqueza de los corderos del pastor Menalcas. Efectivamente, hay miradas que afectan el estado anímico o hasta la salud de las personas, y más si son muy vulnerables como los bebés. Es por esta razón que hay amuletos como el azabache (introducido por los árabes a España en el siglo XVI) o el uso de un nazar u ojo turco, que aún se usa en muchas culturas para protegerse del llamado "mal de ojo", "fascinación" u "ojeada" que alude, finalmente, a una protección 
frente a la envidia humana ${ }^{4}$, cualidad que poseen algunos, concretamente quienes tienen ojos de colores claros (Gutiérrez, 1980), y cuya descripción aproximada puede ser esta: /foco visual fijo y directo/+/expresiones faciales tensas/+/configuración física particular/.

Incluso, en las creencias y actuaciones de nuestra cultura popular, las víctimas de la llamada "ojeada" suelen ser críos de corta edad, quienes, una vez 'ojeados', presentan síntomas como llanto sin causas concretas, fiebrecillas, vómito y hasta enfermedad diarreica aguda. Según las personas que aseguran tratar este tipo de casos, la mejor manera de cerciorarse de que un niño ha sido víctima del "mal de ojo" es midiendo sus dos piernas, si una de ellas es significativamente más larga que la otra es indudable que el 'mal' está presente.

La mirada también ha sido preocupación de los filósofos existencialistas, como el caso de Sartre (2008), para quien la mirada tiene que ver con los juegos de la libertad y de la pérdida del Otro; la de los psicoanalistas, como el de las primeras enseñanzas de Jacques Lacan sobre la fase especular del niño y la configuración del Yo, donde la mirada de la madre es el espejo en el cual se mira el bebé; por eso hay una época en la que si el crío sonríe, la madre sonríe, y si llora, la madre se pone triste. Pero también cabría tener en cuenta las reflexiones de los psicólogos en general con la mirada fetichista (el objeto mantiene fascinado al sujeto y lo obliga a detenerse en él) o la de los filósofos modernos, como Michel Foucault (2002) cuando habla de la mirada que lo quiere ver todo para llevar procesos de vigilancia, control y castigo, tipos de mirada abstracta, pero real que se hace visible en los Reality shows; pero también en las imágenes en directo sobre los bombardeos de las guerras de Irak o Afganistán o en las noticias que muestran aquellos vídeos-escándalo en política latinoamericana, para citar algunos ejemplos puntuales.

En cuanto a las expresiones faciales, al igual que las miradas, manifiestan información de tipo emocional y suelen pertenecer tanto al mundo de la gesticulación, como al mundo de los ilustradores y los emblemas, preferentemente. El psicólogo Ekman $(2009,2012)$ es uno de los investigadores que más ha trabajado la relación expresión facial-emocionalidad. De hecho la popular serie televisiva Lie to me/Miénteme, emitida por la cadena FOX (2009-2011), está basada en sus estudios y relieva las formas de dar sentido a las microexpresiones involuntarias. A Ekman, precisamente, debemos el término 'emociones básicas' que dan cuenta del papel que la evolución ha jugado en formar la expresión y la función de las emociones (rabia, repugnancia, miedo, alegría, tristeza y sorpresa).

4 Envidia (in-videre: ver contra alguien, mirar con ojos malos). La palabra se adoptó al español en el siglo XIII, por el poeta español Gonzalo de Berceo, del llamado Mester de Clerecía. 
Asimismo, es común seguir pensado en que ciertos engranajes sintácticos del rostro humano revelan ciertos aspectos esenciales de la personalidad intrínseca de los sujetos. Esto se lo debemos a Aristóteles, para quien "[...] todas las pasiones del alma se encuentran vinculadas con un cuerpo, pues, cuando se producen, el cuerpo experimenta una modificación" (1988, p. 15). En esa medida, la fisiognomía se hace una axiología, pues se establece una relación semiótica entre los elementos del rostro y los rasgos del carácter, gracias a mecanismos de conjetura basados en relaciones de implicación y asociación heredada (Magli, 1990). Así, por ejemplo, las cejas gruesas se coligan con la severidad, los dientes largos con la amenaza, el cabello abultado y desordenado con el terror, los labios gruesos con la sensualidad o las múltiples cualidades físicas de la nariz con cualidades de personalidad (nariz cóncava, tranquilos; convexa, nerviosos; ancha, curiosos; puntiaguda, imaginativos; respingona, frívolos; redondeada, bondadosos, etc.).

Este simbolismo moral del rostro se desarrolló durante el siglo XVI con el trabajo del filósofo natural italiano Giovanny Della Porta, quien estudió cómo la fisonomía permitía, tras la fijación de ciertas normas semánticas, establecer rasgos esenciales del sujeto. La herencia de Della Porta se evidenció a finales del siglo XIX y comienzos del XX, con la sedimentación de la criminología que abandera no solo investigaciones sobre delincuentes, sino que también intenta corregir el comportamiento antisocial del hombre, y a la cual se han unido otras disciplinas, algunas veces tratadas de pseudociencias, tales como la personología, que estudia las correlaciones entre la apariencia física de una persona, su personalidad y sus actuaciones sociales; la morfopsicología, que estudia las relaciones entre las características morfológicas del rostro de una persona y su perfil psicológico; la craneometría, usada por los nazis para diferenciar por las medidas del cráneo a arios de quienes no lo eran; o la frenología, que clasifica las personalidades por la forma del cráneo y las facciones. $Y$, aunque esto parezca caduco o pseudocientífico, en la actualidad hay investigadores que siguen estudiando fenómenos comprometidos con la fisiognomía. Por ejemplo, en enero de 2013 salió un resultado de investigación liderado por prestigiosas universidades estadounidenses que sugiere:

[...] una relación entre la forma de la cara y la personalidad, presentados sobre todo por varias universidades estadounidenses aseguran que los hombres con caras más anchas tienden a ser más agresivos [...] también sostienen que la mayoría de mujeres prefiere a hombres con estos rasgos, ya que la agresividad se asocia con una mayor capacidad reproductiva. (ADN, 21.01.13).

5 Fisiognomía es el estudio del carácter a través del aspecto físico y, sobre todo, a través del aspecto particular de rostro del individuo (fisonomía). 


\subsection{La proxemia}

En cuanto al sub-nivel proxémico, dentro del orbe prelingüístico, tenemos que, dependiendo de las formas de organización del espacio en la comunicación a través de las relaciones de proximidad o alejamiento durante la interacción, los sujetos podemos comunicar cierto tipo de informaciones. Esto es lo que se aborda en la proxémica, disciplina que estudia el comportamiento no verbal relacionado con el espacio personal. Ahora, al igual que con la forma de tratamiento en el orbe quinésico, en el proxémico tenemos una clasificación posible de unidades de análisis, esta vez construida de forma más local para los propósitos del artículo, y que llamaremos en adelante proxemas. Nuestra propuesta se resume en el siguiente cuadro:

\begin{tabular}{|l|l|l|}
\hline \multicolumn{1}{|c|}{ Proxemas } & \multicolumn{2}{c|}{ Subcategorías } \\
\hline \multirow{2}{*}{ Empatía } & Inmediación & \multicolumn{1}{c|}{ Proximidad lejanía } \\
\cline { 2 - 3 } & $\begin{array}{l}\text { Relajación } \\
\text { corporal }\end{array}$ & $\begin{array}{l}\text { Posición más abierta o más cerrada. Una posición abierta implica que } \\
\text { brazos y piernas no separan a un interlocutor de otro, la posición } \\
\text { cerrada implicaría utilizar las piernas, brazos o manos en forma de } \\
\text { protección o de barrera }\end{array}$ \\
\hline \multirow{2}{*}{ Estatus } & Congruente & Sujetos de estatus similar (gestos, postura y estéticas similares) \\
\cline { 2 - 3 } & Incongruente & Sujetos de diferente estatus \\
\hline \multirow{2}{*}{$\begin{array}{l}\text { Óngulo de } \\
\text { perientación o }\end{array}$} & Recta & Conversación cara a cara \\
\cline { 2 - 3 } & O grados & Se sientan uno al lado del otro \\
\cline { 2 - 3 } & Caballera & Cuerpos relativamente rectos $\left( \pm 45^{\circ}\right)$ \\
\hline
\end{tabular}

Cuadro 2. Tipología de proxemas. Elaboración del autor

Ahora bien, al igual que con los quinemas, los proxemas emergen en las situaciones comunicativas de manera simultánea, y su análisis obliga a determinar asociaciones que evidencia su afinidad descriptiva. Así, por caso, a mayor empatía, mayor confianza y mayor congruencia con orientación cero grados; mientras que a menor empatía, menor confianza y mayor incongruencia con orientación recta (o caballera).

El proxema de la empatía es uno de los más estudiados en relación con las descripciones y los análisis de este sub-nivel lingüístico. Este acentúa el asunto de las "burbujas vitales" desarrollado por el antropólogo Edward Hall (1999) y, por tanto, con el concepto de distancia corporal, la cual cambia por los grados de empatía posibles; pero, también, por las condiciones de interacción guiadas por una necesidad biológica ${ }^{6}$. Al

6 Efectivamente, resultados de experimentos con animales abigarrados en espacios estrechos por mucho tiempo, dejan ver cambios 
respecto, Albaladejo (2007) afirma "[...] Hall se dio cuenta que el individuo humano se desplaza dentro de una especie de burbuja privada, que representa la cantidad de espacio que siente que debe haber entre él y los otros" (p. 109).

Así las cosas, se habla de una distancia pública (+ $3 \mathrm{~m})$, como la que se establece entre discursos de persuasión o convicción; una distancia social $(1-3 \mathrm{~m})$ generada por jefes-empleados 0 en las entrevistas; una distancia personal $(50 \mathrm{cms}-1.20 \mathrm{~m})$, fundada entre amigos, reuniones de trabajo, reuniones familiares o fiestas; y, finalmente, una distancia íntima $(15-45 \mathrm{~cm})$, que se evidencia entre parejas enamoradas y entre padres e hijos. Tal como se ha advertido, si bien estas distancias tienen un componente biológico, así que si no se respetan prudentemente, pueden llegar a generar un colapso conductual. También es cierto que estas distancias dependen también de tradiciones socio-culturales. Esto es lo que permite hablar de 'culturas de no contacto', donde el espacio íntimo entre europeos y anglosajones llega, con suerte, a 25 centímetros y 'culturas de contacto', como la de los árabes y los latinos, donde es evidente que todas las distancias son más cortas, fundando lazos de afecto hiper-íntimo. Así las cosas, si alguien invade o hace "avances" al espacio íntimo, esto se interpreta como que tiene interés en esa persona y es decisión del otro aceptar o no esos acercamientos a su burbuja; y si el "invadido" se echa para atrás, el mensaje también es claro.

\subsection{Sobre las fronteras gestuales y dialectos}

A todo lo anterior, habría que advertir que todos los quinemas y proxemas, independientemente de su cualificación taxonómica, están sometidos a la variación semántico-pragmática. Por ejemplo, esto significa que un mismo quinema significa algo diferente según el contexto geográfico y/o cultural donde se produzca; esto es, su significado se da de diferentes formas significantes, según el límite regional o nacional. Por ejemplo, el siguiente quinema-emblema, conocido como el gesto del aro, y cuya descripción es:

/el antebrazo rígido a la altura del cuello/ + /palma abierta y hacia afuera + / dedos pulgar e índice enroscados en forma de anillo/ + /dedos medio, anular y menique erguidos en forma de abanico/?.

de conductas; entonces los animales violan, asesinan, se deprimen, se vuelven homosexuales gracias a una actividad exagerada de las glándulas suprarrenales. Al transpolar esto a la especie humana, se ve cómo a medida que aumenta la población, los individuos se sienten más amenazados y reaccionan agresivamente. Muchas veces esa agresión se interioriza y se llega al suicidio. No gratuitamente, en Tokio hay un millón de suicidios al año, un territorio geográfico de apenas 570 kilómetros cuadrados y donde moran 13 millones de personas, mientras que en Bogotá, con 1587 kilómetros cuadrados y con un promedio de 9 millones de ciudadanos, se registran aproximadamente 90 casos de suicidio por año (Cfr. Albaladejo, 2007).

7 Se ha tomado lo básico de las entradas léxico-gestuales sugeridas por Meo-Zilio y Mejía (1980), pero se ha alterado su forma de presentación, al introducir en los artículos los diacríticos / /+//, para así, facilitar su lectura y acercarla más a la técnica de trascripción fonológica usada en los manuales. 
Entre los habitantes de las campiñas británicas y para la mayoría de los sujetos este gesto significa que "todo está/va bien", esto es, es un símbolo de "OK" ("de acuerdo"), y que tuvo su origen en la fijación intencionalmente mal escrita de las iniciales "All Correct", en el diario Boston Morning Post, en 1839, con el fin de generar humor en los lectores de sus textos. Sin embargo, en la isla italiana de Cerdeña, en otros muchos otros lugares de la zona Mediterránea, además de Alemania, Rusia y Medio Oriente, "OK” es un gesto de obscenidad e impudicia (el círculo allí formado equivale a mostrar un orificio corporal). Aún más:

[...] En la actualidad, se acostumbra a utilizar como signo de que alguien piensa de otro que es homosexual, o al menos afeminado. En algunas zonas de Francia y Bélgica se utiliza para señalar que algo es insatisfactorio; en este caso el círculo es un cero. En Japón, el anillo simboliza una moneda, y el mensaje del gesto es dinero. En Inglaterra, existe ahora una nueva versión popular del signo del círculo, que consiste en agitarlo espasmódicamente, imitando el movimiento de la mano durante la masturbación masculina. (Morris, 2009, p. 202).

Así las cosas, completando el artículo léxico-gestual para rangos mundiales tendríamos algo así como lo siguiente:

/antebrazo rígido a la altura del cuello/ + /palma abierta y hacia afuera + /dedos pulgar e índice enroscados en forma de anillo/ + /dedos medio, anular y menique erguidos en forma de abanico/: mayor parte del globo ("todo va bien"), Al., Rus, Or. Med., Ital. vulg. ("iVete al carajo!", “imétetelo por el culo!”), Fr., Bélg. ("Nada”, sin valor"), Jap. ("Dinero") "Afeminado" [Ing.]; vulg. /fest. \/antebrazo rígido a la altura del cuello/ + /palma abierta y hacia afuera/ + /dedos pulgar e índice enroscados en forma de anillo/ + /dedos medio, anular y menique erguidos en forma de abanico/ + /agitar la mano de forma diagonal varias veces/ [Ing.]8.

Es por eso que frente al análisis de los quinemas, lo más frecuente es encontrar los aloquines; esto es, variantes de los quinemas, de la misma forma que en los análisis fonológicos de los sonidos de una lengua, se encuentran alófonos, dando origen a la disciplina de la fonética. Estos aloquines se dan como 'gestos regionales o nacionales' que permiten prever 'fronteras gestuales'. Otro ejemplo simple, pero contundente, de esta presencia de gestos nacionales son las múltiples ejecuciones del gesto saludo, donde las manos ocupan el papel principal y puede tomar la cualidad de regulador, adaptador, emblema o ilustrador, según sea el caso y el país o cultura nacional, dado que envían

8 significa sinónimo del gesto y significa una variante moderna del gesto del aro en la diatopía Inglaterra (Ing.), en contextos vulgares y festivos (cuyas marcaciones pragmáticas son vulg. y fest.) 
señales visuales a los interlocutores, pero no siempre con el mismo significado. Así por caso, el ejemplo que desarrolla Morris en su documental "El mono desnudo: el lenguaje del cuerpo" (1994) ${ }^{9}$, realizado para la British Broadcasting Corporation (BBC):

- Estrecharse rápidamente las palmas de las manos, como sucede entre los Massai, que viven en Kenia meridional y en Tanzania septentrional.

- Estrecharse la mano derecha, mientras la izquierda toca el antebrazo, entre habitantes de Malí, en África Occidental.

- En Marruecos, a la vez se dan la mano, se besan el dorso de las mismas.

- En Turquía saludarse es una regla inviolable que no se puede iniciar un negocio sin apretarse las manos fuertemente y no se pueden soltar hasta que no se cierra el trato comercial.

- Saludos en Medio Oriente. La mano derecha se desplaza hacia arriba, tocando la zona del corazón, después la frente, mientras se dice la frase 'salaam alaykkum' (la paz sea contigo).

- En la antigüedad, el saludo lo daban las clases bajas a sus maestros y señores; tal como sigue sucediendo actualmente en la India, donde el señor alza el pie y el súbdito, arrodillado, besa la región del tarso anterior.

En este orden de ideas, los gestos regionales generan fronteras gestuales; esto es, isoglosas quinésicas, para emplear el término dialectológico ${ }^{10}$, donde se pueden discernir y describir dialectos gestuales. Siguiendo a Morris (1994, 2009), los gestos regionales se confinan en una zona en particular y se conservan por muchos siglos; incluso, son inmunes a los modelos quinésicos transmitidos por los mass media. Así, por caso, en Nápoles, al sur de Italia, se usa el cabezazo para decir "No", mientras que en Roma, la cittá eterna, un poco más al centro usa el movimiento horizontal o de lado a lado para comunicar una negación; pero, es en el norte de Italia, en las sierras de Massa, región de la Toscana, donde sus 70.000 habitantes, aproximadamente, unen los dos gestos, el cabezazo y el movimiento horizontal, para decir "No", haciendo que sus gestos de afirmación como los gestos de negación sean muy complicados para alguien que no sea nativo ${ }^{11}$.

9 En realidad es una colección de seis documentales, basada en la obra El mono desnudo (The Naked Ape, 1967). En su orden, los títulos de la colección son: (i) El lenguaje del cuerpo, (ii) El mono cazador, (iii) El zoo humano, (iv) La biología del amor, (v) los genes inmortales y (vi) Más allá de la supervivencia.

10 Se entiende por isoglosa una línea imaginaria que separa dos áreas geográficas que se distinguen por un rasgo dialectal concreto, en este caso no fonético ni lexical, sino gestual.

11 Nótese que con este caso, se reevalúa el lugar común de creer que el gesto de afirmación (cabezazo) y de negación (movimiento 
De esta manera, es como aparece la frontera o isoglosa gestual; esto es, lugares geográficos donde acaban unos gestos y comienzan otros. La explicación de este ejemplo es histórica. En un principio el cabezazo para decir que "No" era un gesto de los griegos, quienes conquistaron el sur de Italia (Sicilia) hacia 735685 a. C., y avanzaron hacia el norte y fue, justamente, en la sierra de Masso donde detuvieron su avance hace un poco más de 2500 años. Sin embargo, en el sur se mantiene el antiguo gesto griego de negación y en el norte no (para lo cual se mueve la cabeza de lado a lado); pero en esos pocos kilómetros y habitantes de Masso sobreviven los dos gestos. Es así como la antigua frontera gestual permanece.

Ahora bien, siguiendo esta idea, es posible pensar la proyección de un Atlas lingüístico etnográfico y diacrónico de gestos (ALEG) para cada país, o para el globo terráqueo en general, puesto que eso es lo que se sugiere desde esta pareja conceptual frontera quinésica-dialecto gestual. Pero también es evidente, tal como sucede con el nivel lingüístico de las lenguas-idioma (fonético, sintáctico, léxico-semántico, etc.) en subdialectos gestuales e, incluso, en jergas o argots gestuales. Para esto último es posible pensar en cómo, por caso en esas modalidades de gestos de grupos bien delimitados de la sociedad, como ciertos colectivos de delincuentes, tal como sucede con los sub-códigos gestuales creados por las pandillas Sureñas, en California, donde los jóvenes usan gestos manuales específicos para comunicar su afiliación con la cuadrilla, para comunicarse a distancia o para hacer amenazas a las pandillas rivales; todo esto acompañado de otros eventos quinésicos como la forma de cruzarse de brazos, lo erguido de sus cabezas, el porte que simula una actitud desafiante, etc.

De ser así, planteamos que en el artículo léxico-gestual por construir en este tipo de casos, debería sumarse la variedad diastrática con los valores de culto (cult.) o vulgar (vulg.) y, en caso de precisar el origen de jerga, que se incluya la información entre paréntesis. Así, por ejemplo, delincuentes (delinc.), drogadictos (drog.), pandillas juveniles (pand.), etc. Esto mismo sucede para los proxemas; de hecho, pensamos que los aloproxes dependerían de las variantes presentes en reglas de interacción topo-corporal como:

- Ganar un espacio entre extraños, donde se busca un espacio vacío alejado de la multitud como un bus, el aula, un parque, una sala de espera, etc. (empatía).

de lado a lado) son universales. En la India, por ejemplo, pasa justamente lo contario: en lugar de mover la cabeza de un lado a otro para comunicar "No", lo usan para hacer afirmaciones, incluso absolutas. Incluso, en Bulgaria, se usan estos gestos para afirmar, haciendo que esto sea muy complejo de interpretar para quien desconoce esta herencia quinésica. 
- La armonía social, donde la distancia es, en todo caso, (im)predecible; a pesar de esto, un sujeto no se sitúa demasiado lejos de los otros, incluso si son extraños, puesto que se puede interpretar de manera ofensiva (estatus).

- La distancia frente a la autoridad, donde los sujetos tienden a ubicarse de cierta manera frente a un profesor/conferencista, dependiendo del interés de participación en el evento (ángulo de orientación).

\section{Referentes metodológicos}

A partir de estas determinaciones teóricas, y dentro del marco de la investigación "Textos creativos y la identidad social en Colombia", auspiciado por el CIDC de la Universidad Distrital (2013-2015), se generó la pregunta por aquellas unidades de la lengua-sistema (en los niveles verbales y no-verbales) que reflejan ciertos rasgos sociales identitarios de nuestra cultura, sumado a la inquietud de cómo estos se leían críticamente apoyados en posturas disciplinares (semióticas, antropológicas, etc.).

Tal intención se instaló en un área metódica que comprometió la investigación en el paradigma hermenéutico, pues el papel del investigador fue el compenetrarse con la realidad que observaba para comprender el suceso estudiado (Taylor \& Bogdan, 1986); paradigma que suele aprovechar frecuentemente el método cualitativo, usado para describir la realidad fijada a través de la recolección de datos obtenidos gracias a la observación participante, las entrevistas y la selección de artefactos e instrumentos para recoger información que circula colectivamente en diferentes medios y mediaciones comunicativas (Hernández Sampieri, et. al. 2008). Todo esto, mientras que el diseño elegido fue inicialmente el etnográfico, complementado con el del análisis discursivo, herramientas que auxiliaron tanto el acceso al material simbólico-cultural recogido con el apoyo de instrumentos propios de la etnografía general, así como su descripción semio-linguística para, posteriormente, ser sometido a una determinación formal y a un análisis de su función social o intencionalidad en situaciones de la conversación cotidiana e inmediata (Cortés y Camacho, 2003). Con esta mixtura de diseños se logró una contextualización, profundidad y riqueza interpretativa de los datos, originalmente lingüísticos.

Ahora bien, para avanzar en la investigación tras la maduración teórica, se delimitó un depósito de material de trabajo o corpus lingüístico, condensado en registros audiovisuales y resultados escritos de entrevistas que indagaban por gestos, posturas corporales, además de expresiones frecuentes y subjetivamente características presentes en la comunicación cotidiana. Todo esto estuvo guiado por criterios sociolingüísticos que ayudaron a la 
codificación de fenómenos comunicativos pertenecientes a los niveles pre y para lingüístico, y también del nivel lingüístico, y que fueron indagados en hablantes inscritos en fronteras gestuales e isoglosas céntricas de Colombia. En el caso de los ejemplos elegidos aquí para su análisis contextual o discursivo, se fijó una muestra de quinemas, proxemas y morfemas frecuentes en hablantes que moran en la isoglosa del dialecto andino oriental colombiano, subdialecto cundiboyacense, con diastratía vulgar y diafasía coloquial, caracterizados por lo que Berstein (1989) llamó hablantes de código restringido.

Una vez capturadas, determinadas, seleccionadas y codificadas las unidades de análisis, se sometieron a un examen guiado por premisas del orbe teorético del Análisis discursivo, resumido en tres grandes momentos, así:

\begin{tabular}{|c|c|l|}
\hline $\begin{array}{c}\text { Dimensión } \\
\text { discursiva }\end{array}$ & Ámbito & \multicolumn{1}{c|}{ Acción básica de análisis } \\
\hline $\begin{array}{c}\text { Uso } \\
\text { lingüístico }\end{array}$ & Estructural & $\begin{array}{l}\text { Determinación de las unidades constitutivas del discurso } \\
\text { por nivel (no verbales y verbales) }\end{array}$ \\
\hline Práctica discursiva & Socio-cognitivo & $\begin{array}{l}\text { Alerta y análisis connotativo-asociativo de elementos como } \\
\text { simbolismos, imaginarios, valores, ideologías, intertextos, } \\
\text { etc. }\end{array}$ \\
\hline $\begin{array}{c}\text { Práctica } \\
\text { social }\end{array}$ & Cultural & $\begin{array}{l}\text { Dialogismo entre los sentidos tejidos inferencialmente y el } \\
\text { marco socio-histórico y cultural de enunciación. }\end{array}$ \\
\hline
\end{tabular}

Cuadro 3. Modelo de análisis discursivo propuesto para unidades pre-linguiísticas

Una vez esbozado este modelo, es significativo aclarar que no siempre es fácil, en la práctica, separar el segundo momento del tercero, dado que muchas de las connotaciones sobre el material significante del corpus atesoran sentido(s) en el marco de ciertos contextos socio-históricos determinados, haciendo que frecuentemente la combinación 0 trabajo semántico proyecte elementos que se trabajan en la interpretación y estos, a su vez, ya toman forma y contenido en el empalme con los posibles eventos y sucesos históricos que aquí se capturan desde voces de sujetos que pertenecen al mismo contexto y, por tanto, comparten los mismos esquemas culturales y conocimientos socioculturales.

\section{Análisis de dos casos}

Ahora bien, aprovechando toda la información de la que disponemos preferentemente sobre los orbes quinésico y proxémico en la comunicación oral, se puede afirmar que los fenómenos linguísticos reflejan aspectos de la identidad social. Por tanto, (re)conocer elementos de la lengua en contextos comunicativos cotidianos es interpretar idiosincrasias de sus hablantes (Morant, 2005). 
Así, la identidad social es una creación lingüística en dos sentidos: por un lado, se funda usando la lengua y sus componentes verbales y no verbales y, por otro, se refleja en cada elemento constitutivo de la lengua, rehaciéndola constantemente. De esta suerte, el uso social de la lengua termina siendo, entonces, creadora de identidad nacional y, al tiempo, marca distintiva de la misma. Coincidimos con Hall y Du Gay (2003), quienes afirman que la identidad de una nación no es una realidad trascendente y a-histórica, sino el resultado cambiante de un continuo proceso de producción y transformación de significados fundados dentro de los eventos discursivos a lo largo del a historia.

Más conveniente es recordar las ideas del dialectólogo Montes Giraldo (1993, 2010), quien afirma que, a pesar del mosaico étnico y geográfico de Colombia, se puede entrever una identidad social que, aunque no única, fija y coherente, sí permite legítimamente postular "el reflejo en la lengua (al menos en algunas parcelas lingüísticas) del vivir histórico de un pueblo" (2000, p. 150). Incluso, si bien es cierto que resulta problemática la idea general de que la identidad nacional del colombiano está reflejada en rasgos comunes a todos sus 47 millones de habitantes y es exclusiva de ellos, "sí es evidente y demostrable con multitud de fenómenos, entre ellos los lingüísticos (dialectales), la identidad regional de Colombia” (Montes, 2000, p. 151).

De esta suerte, se puede sostener que hay una conexión entre fenómenos de la lengua y la identidad de esos hablantes-usuarios de la lengua en cuestión; lo que se corrobora claramente en los países multilingües y multiétnicos, en los cuales cada grupo siente que la conservación y la defensa del idioma es el mejor camino para mantener su rostro cultural. En suma: "[...] la idea general es que determinados rasgos lingüísticos identifican una serie de dimensiones como nación, filiación étnica, estratificación social, grupo social, edad y sexo" (Patiño Roselli, 2004, p. 54).

Para ahondar en esto último, revisamos rápidamente el ejemplo que, a nivel morfológico de la lengua española, dialecto andino, subdialecto cundiboyacense, manifiestan los hablantes, especialmente las mujeres de diastratías desfavorecidas y diatopías periurbanas, y es su tendencia al uso excesivo del sufijo derivativo diminutivo. No es gratuito, entonces, que esto refleje nuestra tendencia al pensamiento y acción estrechas, como bien lo revela el semiólogo Armando Silva, cuando se refiere al sistema masivo de transporte en la ciudad de Bogotá, el TransMilenio:

Bogotá es la única capital de Suramérica con más de cuatro millones que no tiene metro (excepto Lima, por problemas de suelo). Se nos dice que somos pobres, como si las ciudades que lo han hecho no hubiesen pasado por un esfuerzo inicial que luego se compensa. Me temo que es asunto de mentalidad. Nuestra historia está llena de soluciones 
diminutas. Basta mirar las calles de nuevos barrios, estrechas como las de la colonia, o la ampliación del aeropuerto El Dorado, que apenas quedará como el de Quito, o, incluso, el uso del lenguaje y comprobar cómo pega el diminutivo para decir chiquito, gordita [...] (Silva, 2 de junio de 2007) ${ }^{12}$.

Pero, en esta misma lógica de lectura sobre prácticas discursivas y sociales, podemos recuperar dos casos, uno en el sub-nivel quinésico y otro en el proxémico, para dar cuenta de lo que aquí suponemos como reflejo identitario social en fenómenos de habla. El primero tiene que ver con el siguiente gesto batuta o ilustrador:

/a palma de la mano hacia arriba/ + /os cinco dedos unidos por sus yemas/ + / movimiento armonizado de dedos fuera-dentro/ + /a enunciación de la expresión "se le hace así... gallina"/: Col. ("persuasión para la ejecución de actos violentos")

Este primer caso remite a una cualidad de nuestra identidad social, a saber: la dominancia de elementos centrados en la presencia continua de la violencia simbólica y real frente al otro, que sirve de pivote para la proyección de una cultura del bravío y el machote, quien, obsesionado por las empresas desacertadas, y con auxilio de las armas de fuego, mantiene una interacción social sin hilos históricos anudadores (García-Dussán, 2013). Se mantiene así, el cultivo de una reciedumbre como condición de búsqueda, mando y defensa que se visibiliza en explosiones ocasionales de masculinidad y que obliga a aceptar como figuras de identificación toda forma de autoridad, mientras sea lo bastante viril, como sucede actualmente con el fútbol.

El segundo caso, es la disposición del cuerpo de un transeúnte colombiano caminando por la calle de una ciudad en la noche, quien, en relación con otro cuerpo cercano que funge como sistema de referencia, tiende a alejarse suficientemente, invirtiendo así una lógica urbana simple: la de caminar por la acera para pasar a caminar por la mitad de la calle. Entonces, lo que sirve para el tránsito de coches, se convierte en tránsito de los urbanitas.

Esta postura, que bien puede ser atribuida a una descripción y un análisis proxémico, pues en este tipo de encuentros, de interacciones azarosas, es posible interpretar las señales que se despliegan. Para este caso, el hecho de encontrarse a alguien a altas horas de la noche en una calle citadina, se interpreta como que el otro no es amigable, que no se tiene

12 Por cierto, siete años después de la alerta de Silva, es evidente que la ampliación del aeropuerto El Dorado se quedó pequeña: "A pesar de las modernas instalaciones, en las que se invirtieron más de 1.000 millones de dólares -sin contar la nueva torre de control-, la verdad es que el aeropuerto se quedó pequeño para atender el crecimiento exponencial de viajeros, que tomó por sorpresa a todo el mundo" (Revista Semana, 8-IX-2014). 
identificación o empatía con él, para lo cual no hay inmediación, se tensiona el cuerpo y se genera la ambigüedad de mirarlo directamente, pero no por mucho tiempo. Esto se acompaña con una postura que evita estar de frente, pues cuanto más de frente se sitúa una persona hacia otra, mayor es el nivel de implicación. Así que, si el cuerpo se acerca, la posición será muy cerrada y quizá hasta llegue a la posición fetal. Además, un exceso de movimiento incongruente puede producir impresión de inquietud o nerviosismo.

Es así como se despliega un arsenal de categorías proxémicas, tales como empatía, estatus, orientación y del movimiento del cuerpo que ayudan a comprender que la posición corporal adoptada por el transeúnte ya no se define por la disposición de su cuerpo a aceptar al otro en el mismo espacio, rompiendo toda posibilidad de armonía social y de ganancia de espacio entre extraños; se anula, entonces, toda posibilidad de interacción, pues se interpreta, gracias a presuposiciones pragmáticas ${ }^{13}$ que flotan en el ambiente sociocultural de los colombianos, como un delincuente que puede hacer daño.

Así las cosas, al unir los resultados analíticos de los dos caos, tenemos que se unen cualidades caracteriológicas propias, a saber: la constante tendencia a retar al otro para que cree lazos sociales mediados por actos de violencia; unido a la desconfianza primitiva por el otro, porque el otro puede ser, ante todo, enemigo o fuente del mal. Así las cosas, la difidencia frente al vecino 0 al que está al lado se presenta como una manera conductual de definir la otredad en nuestra cultura. Así, pues, si yo me considero bueno, la única forma de asumir la presencia del otro es definiéndolo como malo; algo que a raíz de la teoría de Baumann, podemos denominar, la "gramática de la alteridad del orientalista" (2001, p. 55).

\section{Conclusión}

De las reflexiones anteriores podría deducirse que es legítimo reivindicar, dentro de las prácticas discursivas orales del español hablado en Colombia, al menos en algunas parcelas del nivel prelingüístico en sus ámbitos quinésico y proxémico, el reflejo en la lengua de ciertos rasgos caracteriológicos de nuestro pueblo. Sin duda esta apuesta, que se puede resumir como una ecuación entre lengua-idioma e identidad social de una nación, es y seguirá siendo una postura sociolinguística problemática y necesitará de muchos más matices para poder afirmar que la identidad del colombiano está plenamente irradiada en rasgos realmente comunes a todos los colombianos y con cierta exclusividad de ellos. No obstante, es indiscutible que existe un conjunto apreciable de fenómenos lingüísticos,

13 Entendemos por presuposiciones pragmáticas aquellos implícitos presentes en el discurso; es decir, no inscritas en las representaciones semánticas de los términos, sino dependientes del contexto en el que aparecen. 
dialectales para ser más exactos, elementos de la identidad social de Colombia, pues, finalmente, la sociedad en su conjunto sedimenta rasgos culturales a través de una cierta propagación efectiva que, desde diferentes tiempos y sujetos, terminan invadiendo a toda la sociedad, haciendo que una nación, en perspectiva comunicativa sea un conjunto de acciones discursivas espontáneas que se contagian. La cultura pues, como una 'epidemiología de las conductas no verbales y verbales', siguiendo un poco a Dan Sperber, (1996).

\section{Referencias bibliográficas}

Ackerman, D. (2000). Una historia natural de los sentidos. Barcelona: Anagrama.

ADN (Periódico de Bogotá) Estudio dice que el rostro revela rasgos de la personalidad. Lunes 3 de noviembre de 2013. Disponible en línea: http://diarioadn.co/vida/ciencia/el-rostrorevela-rasgos-de-la-personalidad-1.42394

Albaladejo, M. (2007). La comunicación más allá de las palabras. Barcelona: Grao.

Aristóteles (1988). Acerca del alma. Madrid: Biblioteca Gredos.

Baumann, G. (2001). Tres gramáticas de la alteridad: algunas antropo-lógicas de la construcción del otro en las constelaciones históricas. En Nash, M., y D. Marre. (Edits.). Multiculturalismo y género: un estudio interdisciplinar. Barcelona: Bellaterra.

Benveniste, E. (1989). Problemas de lingüística general I. México: Siglo XXI.

Bernardo de Claraval (1984) De Consideratione ad Eugenium Papam (Tratado sobre la Consideración al papa Eugenio), en Obras Completas de San Bernardo, vol. II. Madrid: BAC.

Berstein, B. (1989). Estudios teóricos para una sociología del lenguaje. Madrid: Akal.

Calsamiglia, H., y Tusón, A. (2002). Las cosas del decir. Manual de análisis del discurso. Barcelona: Ariel.

Cicerón (2006). Sobre los deberes. Madrid: Alianza, clásicos de Grecia y Roma.

Cortés, L., y Camacho, M. (2003). ¿Qué es el análisis del discurso? Barcelona: Octaedro.

Eco, U. (1983). El nombre de la rosa. Barcelona: Lumen.

Ekman, P. (2009). Cómo detectar mentiras. Barcelona: Paidós. 
Ekman, P. (2012). El rostro de las emociones. Madrid: RBA Libros.

Escandel, M. V. (2005). Introducción a la pragmática. Barcelona: Ariel.

Foucault, M. (2002). Vigilar y castigar. Nacimiento de la prisión. Buenos Aires: Siglo XXI.

García-Dussán, É. (2013). Discursos creativos e identidad social en Colombia. En: Pardo, N., García, D., Oteiza, T., y Asqueta, Ma. (Comps.). Estudios del discurso en América Latina. Bogotá: Proceditor.

Gumperz, J. (1982). Discourse Strategies. Cambridge: Cambridge University Press.

Gutiérrez, C. (1980). Los peligros del alma. Visión de un mundo Tzotzil. México: F.C.E.

Hall, E. (1999). La dimensión oculta. México: Siglo XXI.

Hall, S., y Du Gay, P. (2003). Cuestiones de identidad cultural. Buenos Aires: Amorrortu Editores.

Hernández Sampieri, R. et al. (2005, 2008, 2010). Metodología de la Investigación. México: Editorial Mc-Graw Hill.

Jorques, D. (2004). Comunicación y lenguaje. Introducción a los métodos y problemas. Valencia: Tirant Lo Blanch.

Knapp, M. (1982). La comunicación no verbal. El cuerpo y el entorno. Barcelona: Paidós.

Magli, P. (1990). El rostro y el alma. En: Feher, M., y Naddaff, R. Fragmentos para una historia del cuerpo humano. Primera parte. Madrid: Taurus.

Mehrabian, A. (1972). Nonverbal communication. Chicago, IL: Aldine-Atherton

Meo Zilio, G., y Mejía, S. (1980-1983). Diccionario de gestos: España e Hispanoamérica. T1: A-H y T2: I-Z. Bogotá: I.C.C.

Montes Giraldo, J. J. (1993). Idioma, nación, norma, academia: Discurso de posesión como miembro correspondiente de la Academia Colombiana de la Lengua. Bogotá: I. C. C.

Montes Giraldo, J. J. (2010). Otros estudios sobre el español de Colombia. Bogotá: I.C.C.

Morant, R. (2005). Lenguaje y cultura, en García, R. (Ed.) Conocimiento y lenguaje. Valencia: Quiles.

Morris, D. (1977). Manwatching: a field-Guide to human Behavior. London: Jonathan Cape.

Morris, D. (2009). El hombre desnudo. Bogotá: Planeta.

Morris, D. (1994). El mono desnudo: el lenguaje del cuerpo. DVD, rip dual, BBC. 
Patiño Roselli, C. (2004). La función identificatoria del lenguaje. Revista Enunciación, 9, 12-26. Bogotá: UDFJC.

Poyatos, F. (1994). La comunicación no verbal. Madrid: Istmo.

Revista Semana, ¿Se quedó pequeño El Dorado? Sección nación, 8 de noviembre de 2014.

Sartre, J. P. (2008). La náusea. Madrid: Losada.

Schmitt, J-C. (1990). La moral de los gestos. En: Feher, M., y Naddaff, R. Fragmentos para una bistoria del cuerpo bumano. Primera parte. Madrid: Taurus.

Silva, A. (2 de junio de 2007). TransMilenio: la buseta del siglo XXI. Bogotá: El Tiempo.

Sperber, D. (1996). Explaining Culture. A Naturalistic Approach. Oxford: U. K.

Taylor, S., y Bodgan, R. (1987). Introducción a los métodos cualitativos de investigación. Barcelona: Paidós.

Turchet, Ph. (2010). El lenguaje del cuerpo. Madrid: Mensajero.

Virgilio (1990). Bucólicas. Geórgicas. Apéndice virgiliano. Madrid: Gredos.

Zaid, G. (2005). ¿Qué hacer con los mediocres? Letras libres, 41, 32-34. 